\title{
Cyanide removal with a copper/active carbon fiber Cathode via a combined oxidation of a Fenton-like reaction and in situ generated copper oxides at anode
}

\author{
Shichao Tian ${ }^{\mathrm{a}, \mathrm{b}}$, Yibing $\mathrm{Li}^{\mathrm{b}}$, Xu Zhao ${ }^{\mathrm{a}, *}$ \\ ${ }^{a}$ Key Laboratory of Drinking Water Science and Technology, Research Center for Eco-Environmental Sciences, Chinese Academy of Sciences, Beijing 100085, \\ China \\ ${ }^{\mathrm{b}}$ School of Civil Engineering, Hebei University of Technology, Tianjin 300401, China
}

\section{A R T I C L E I N F O}

\section{Article history:}

Received 12 June 2015

Received in revised form 2 September 2015

Accepted 4 September 2015

Available online 7 September 2015

\section{Keywords:}

Cyanide

Hydrogen peroxide

Fenton-like reaction

$\mathrm{Cu}$ electrodeposition

\begin{abstract}
A B S T R A C T
Cyanide is widely present in electroplating wastewater or metallurgical effluents. In the present study, the electrochemical destruction of cyanide with copper/active carbon fiber (Cu/ACF) composite cathode and Dimensionless Stable Anode (DSA) under alkaline conditions was investigated. Firstly, various cathode materials including stainless steel, ACF, copper plate and $\mathrm{Cu} / \mathrm{ACF}$ were compared for cyanide removal. Cyanide removal efficiencies by the individual $\mathrm{H}_{2} \mathrm{O}_{2}$ oxidation generated using ACF cathode or individual DSAs anodic oxidation using stainless steel cathode were less than $20 \%$. Using $\mathrm{Cu} / \mathrm{ACF}$ as the cathode, the removal efficiency of cyanide was largely improved compared with other cathodes. At the current density of $50.01 \mathrm{~A} / \mathrm{m}^{2}$ and the geometric area ratio of $\mathrm{Cu} / \mathrm{ACF}=1: 2$, the concentration of cyanide was lowered from 1.50 to $0.07 \mathrm{mM}$ within 90 minutes. Due to the dissolution of copper plate by the cyanide ions, the concentration of copper ions increased rapidly at first and then decreased with the efficient destruction of cyanide ions. Combined with the SEM-EDX and XPS analysis of the anode surface, it was concluded that the generation of copper oxides occurred at the anode surface, which exhibited catalytic activities for cyanide removal. Meantime, ESR results confirmed the generation of hydroxyl radicals in solution. Hydroxyl radicals generated in the reaction between copper cyanides complexs and $\mathrm{H}_{2} \mathrm{O}_{2}$ were responsible for the cyanide removal. Once the cyanide removal was completed, part of the copper ions was reduced and deposited onto the cathode and part of the copper ions was deposited onto the anode. Therefore, the next recycle for cyanide removal by copper oxides catalytic oxidation at the anode and the Fenton-like oxidation in the solution began. Cyanate was identified as the only product in this system.
\end{abstract}

(c) 2015 Elsevier Ltd. All rights reserved.

\section{Introduction}

Cyanides are discharged by various industries, particularly in metallurgical processes, plating and surface finishing [1,2]. Many strategies have been developed to remove cyanides from wastewater including activated carbon adsorption [3,4], coagulation [5] or ion-exchange [6]. These processes can generate highly concentrated products containing toxic cyanides, which need to be further treated. Alkaline chlorination is widely used for the cyanide removal, which will lead to the formation of toxic cyanogens chloride [7] and chloride disinfection by-products [8]. By contrast, cyanides can be directly converted into less harmful products by

\footnotetext{
* Corresponding author at: P.O. Box 2871, 18 Shuangqing Road, Haidian District, Beijing 10085, China. Tel.: +86 01062849667.

E-mail address: zhaoxu@rcees.ac.cn (X. Zhao).
}

employing oxidation methods, such as ozonation [9], electrochemical oxidation [10,11], photocatalysis [12,13], ferrate oxidation [14,15] and wet oxidation [16].

The electrochemical method was widely investigated for the cyanide and copper cyanide destruction [17,18]. An electrochemical system with stainless-steel anode was generally used for cyanide destruction and copper electrodeposition from dilute wastewater. In the electrochemical removal of copper cyanide complexes, in situ deposition of a copper oxyhydroxide film occurred on the anode, which exhibited electrocatalytic properties for the cyanide removal. The cyanide removal efficiency of the electrochemical process depended on the solution $\mathrm{pH}$, applied potential and the type of the cathode and anode materials [11,19]. The electrochemical removal efficiency of individual cyanide was generally limited. However, In the case of copper cyanide complexes degradation, the cyanide removal efficiency increased 
due to the catalytic process induced by the deposited copper oxides at the anode. With respect to the copper recovery, the deposition of copper ions onto the cathode was desired.

$\mathrm{H}_{2} \mathrm{O}_{2}$ oxidation of several cyanide species had been investigated recently. The direct oxidation of cyanide by $\mathrm{H}_{2} \mathrm{O}_{2}$ proceeded rather slowly [20]. It was known that the non-selective and highly oxidative hydroxyl radicals were formed in the presence of $\mathrm{H}_{2} \mathrm{O}_{2}$ and ferrous or ferric salts, namely Fenton reaction [21]. With respect to the cyanide oxidation, iron cyanide complexes generated, which were known to be refractory and difficult to be furthermore treated. In the case of copper cyanide complexes, it was found that $\mathrm{H}_{2} \mathrm{O}_{2}$ can oxidize $\mathrm{Cu}(\mathrm{CN})_{3}{ }^{2-}$ to $\mathrm{Cu}(\mathrm{CN})_{2}{ }^{-}$. The successive oxidation of cyanide from $\mathrm{Cu}(\mathrm{CN})_{2}{ }^{-}$led to the $\mathrm{Cu}(\mathrm{I})$ liberation. $\mathrm{Cu}(\mathrm{I})$ was oxidized into $\mathrm{Cu}(\mathrm{II})$ with the formation of hydroxyl radicals $(\bullet \mathrm{OH})[22,23]$ through Eqs. (1)-(3).

$\mathrm{Cu}(\mathrm{CN})_{3}{ }^{2-}+\mathrm{H}_{2} \mathrm{O}_{2} \rightarrow \mathrm{Cu}(\mathrm{CN})_{2}{ }^{-}+\mathrm{CNO}^{-}+\mathrm{H}_{2} \mathrm{O}$

$\mathrm{Cu}(\mathrm{CN})_{2}{ }^{-}+2 \mathrm{H}_{2} \mathrm{O}_{2} \rightarrow \mathrm{Cu}^{+}+2 \mathrm{CNO}^{-}+2 \mathrm{H}_{2} \mathrm{O}$

$\mathrm{Cu}^{+}+\mathrm{H}_{2} \mathrm{O}_{2} \rightarrow \mathrm{Cu}^{2+}+{ }^{\bullet} \mathrm{OH}+\mathrm{OH}^{-}$

Therefore, it was proposed that a Fenton-like reaction might occur between $\mathrm{H}_{2} \mathrm{O}_{2}$ and $\mathrm{Cu}(\mathrm{CN})_{3}{ }^{2-}$, leading to the efficient removal of cyanide ions $[24,25]$.

In the current work, the combined cathode of copper plate and activated carbon fiber was designed and used to electrochemically destroy the cyanide ions. This paper investigated the effects of initial $\mathrm{pH}$, current density, geometry area ratio of $\mathrm{Cu} / \mathrm{ACF}$ and stability of the system. Furthermore, the oxidation mechanism was also investigated. By the SEM-EDX and XPS analysis of the anode surface variation, it was concluded that generation of copper oxides occurred at the anode surface, which exhibited catalytic activities for cyanide removal. Meantime, the ESR results confirmed the generation of hydroxyl radicals. The combined action of anode catalysis and hydroxyl radicals oxidation removed cyanide.

\section{Experimental}

\subsection{Reagent}

Sodium cyanide, hydrogen peroxide (30.0 wt.\%), sodium sulfate, hydrogen nitrate and sodium hydroxide were all purchased from Sinopharm chemical regent Co., Ltd., China. The 5, 5-dimethylpyrroline-N-oxide (DMPO) was purchased from the Sigma chemical corporation and stored at $-20^{\circ} \mathrm{C}$. All chemicals were used without further purification and all solutions were prepared using freshly prepared Milli-Q water. $\mathrm{RuO}_{2} / \mathrm{Ti}$ mesh was purchased from Beijing Henglitai Corporation. ACFs were purchased from Nantong Senyou Carbon Fiber Co., Ltd., Nantong, China. A BET specific surface area of the ACFs was $900-1000 \mathrm{~m}^{2} \mathrm{~g}^{-1}$ with a thickness of $1-5 \mathrm{~mm}$. The thickness of Copper plate was about $35 \mu \mathrm{m}$ (Tianjin Fuchen chemical reagents factory).

\subsection{Experimental section}

The experiments were performed in a glass reactor with $200 \mathrm{~mL}$ cyanide solutions. The initial concentration of cyanide ions was $1.5 \mathrm{mM}$. As shown in Fig. 1, $\mathrm{RuO}_{2} / \mathrm{Ti}$ mesh was used as the anode and the various cathode materials including ACF, copper plate were combined with $\mathrm{RuO}_{2} / \mathrm{Ti}$ as composite cathode. In this composite cathode, the $\mathrm{RuO}_{2} / \mathrm{Ti}$ electrode was directly connected to the negative electrode of direct-current (DC) power, which was equivalent to the electron transferring media. The electrochemical experiments were performed at the constant current mode controlled by a DC power (DH1718E-6, Dahua Electronic, Co., Ltd., Beijing, China). Before using the ACFs, the ACFs were cut into pieces with the size of $10 \mathrm{~cm} \times 20 \mathrm{~cm}$ and then kept in boiling water for $1 \mathrm{~h}$ to remove soluble salts. After being dried at $100 \pm 5^{\circ} \mathrm{C}$ for $6 \mathrm{~h}$, the ACFs were further cut into $3 \mathrm{~cm} \times 5 \mathrm{~cm}$ pieces and used as the cathode.

The $\mathrm{pH}$ of cyanide solutions was maintained at alkaline conditions to avoid the release of HCN gas [26]. Therefore, the effect of $\mathrm{pH}$ on the cyanide oxidation was investigated in the $\mathrm{pH}$ range of 10.0-12.0. The $\mathrm{pH}$ was adjusted by $\mathrm{H}_{2} \mathrm{SO}_{4}(0.2 \mathrm{M})$ or $\mathrm{NaOH}$

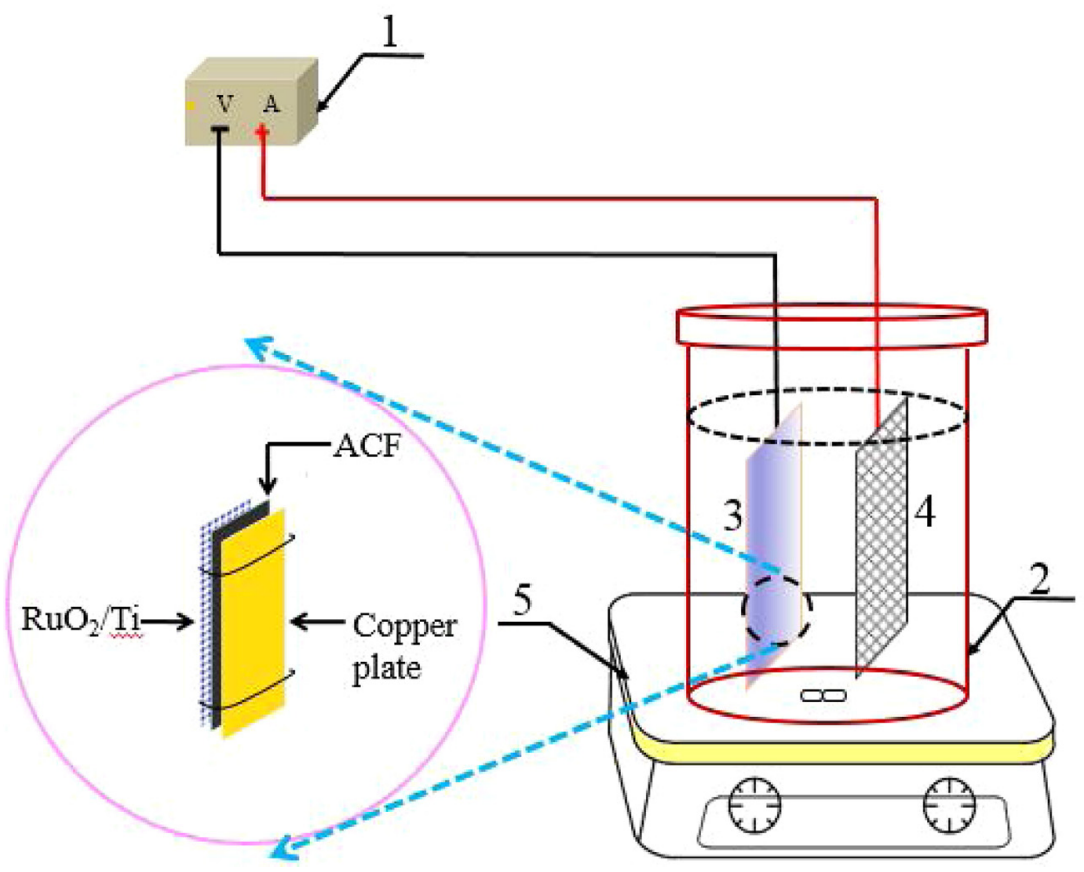

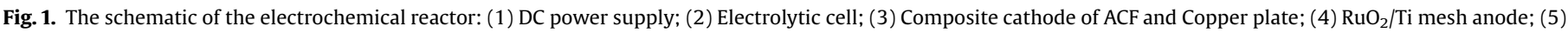
Magnetic stirring apparatus. 


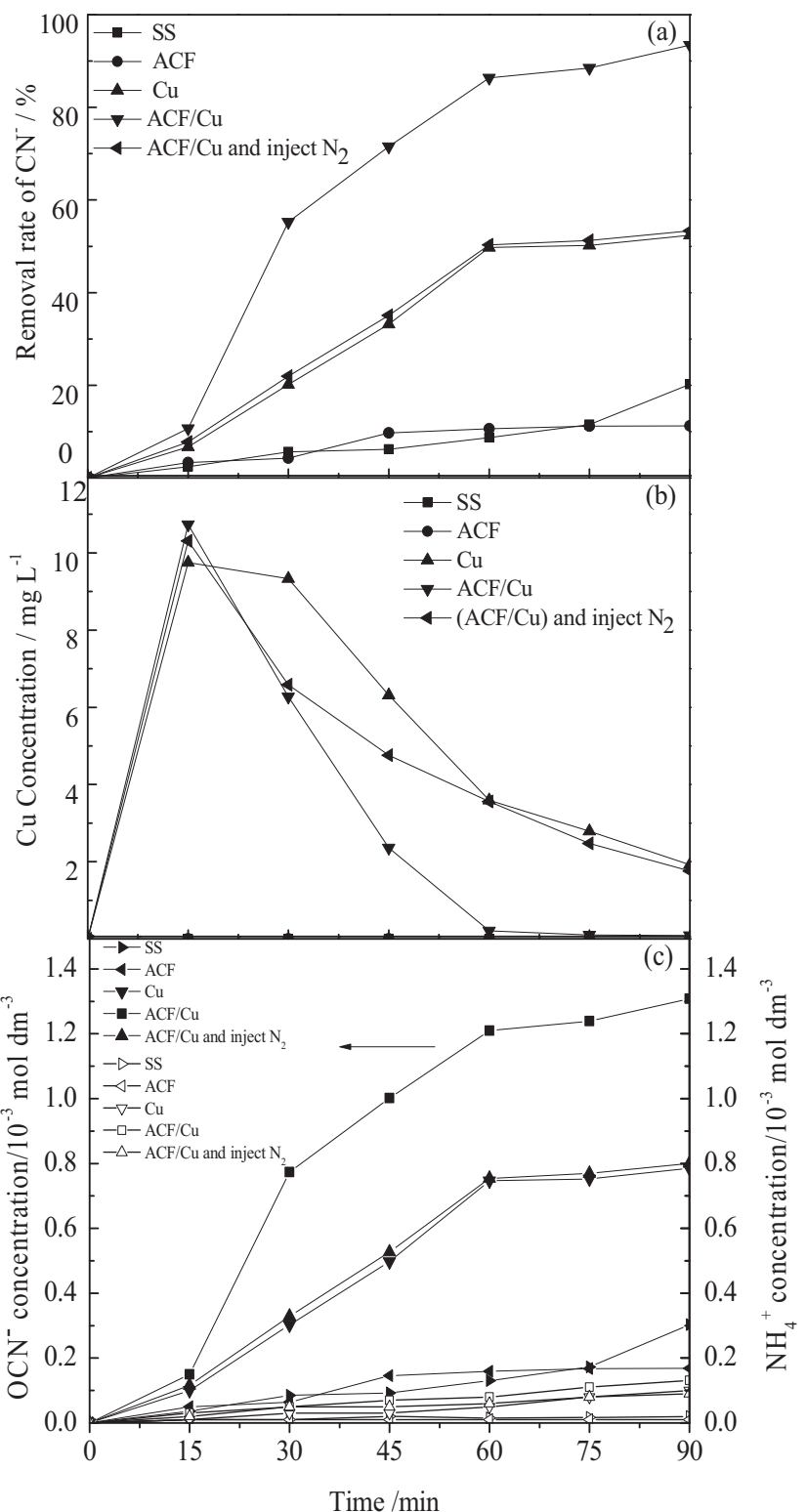

Fig. 2. Effect of various cathode materials on the cyanide removal in the electrochemical process: (a) Removal rate of cyanide; (b) The $\mathrm{Cu}$ concentration in the solution with reaction time; and (c) The $\mathrm{OCN}^{-}$concentration and the $\mathrm{NH}_{4}{ }^{+}$ concentration with reaction time ([cyanide] $=1.5 \mathrm{mM} ;[\mathrm{Cu} / \mathrm{ACF}]=1: 1$; current density $=50.01 \mathrm{~A} / \mathrm{m}^{2} ; \mathrm{pH}=12.0$ ).

solution $(0.2 \mathrm{M})$. During all the experiments, the concentration of cyanide (or cyanate) was measured at the given time.

\subsection{Analytical procedures}

The total cyanide concentration was determined by the colorimetric method at $610 \mathrm{~nm}$ after the distillation procedure [27]. Cyanate concentration was determined by hydrolyzing to ammonia at acidic pH (1.5-2.0) and ammonia was measured by UV-vis spectrometer (Hitachi U-3010) at $420 \mathrm{~nm}$. Total $\mathrm{Cu}$ ions concentration was measured using a 700 series inductively coupled plasma optical emission spectrometer (ICP-OES, Agilent Technology, U. S. A). The solution $\mathrm{pH}$ value was adjusted to be 12.0 and was measured by a standard $\mathrm{pH}$-meter (310P-02, Thermo Fisher, U.S.A.). Hydroxyl radicals were detected by electron spin resonance (ESR) (Bruker ESP-300E). The deposition on the anode and the reduction of the dissolved $\mathrm{Cu}$ ions in the ACF cathode were checked by scanning electron microscope (SEM, model 6700F, Tokyo, Japan) and energy dispersive X-ray analysis (EDX) (JEOL, Japan). X-ray photoelectron spectra (XPS) was also used to analyze the surface variation of the cathode and anode using a PHI Quantera SXM (PHI-5300/ESCA, ULVAC-PHI, INC).

\section{Results and discussion}

\subsection{Comparison of cathode materials for cyanide removal}

Various cathode materials including stainless steel, activated carbon fibers, copper plate and the combination of copper plate with ACF $(\mathrm{Cu} / \mathrm{ACF})$ are firstly compared for the destruction of cyanide ions in the same electrochemical system under the same
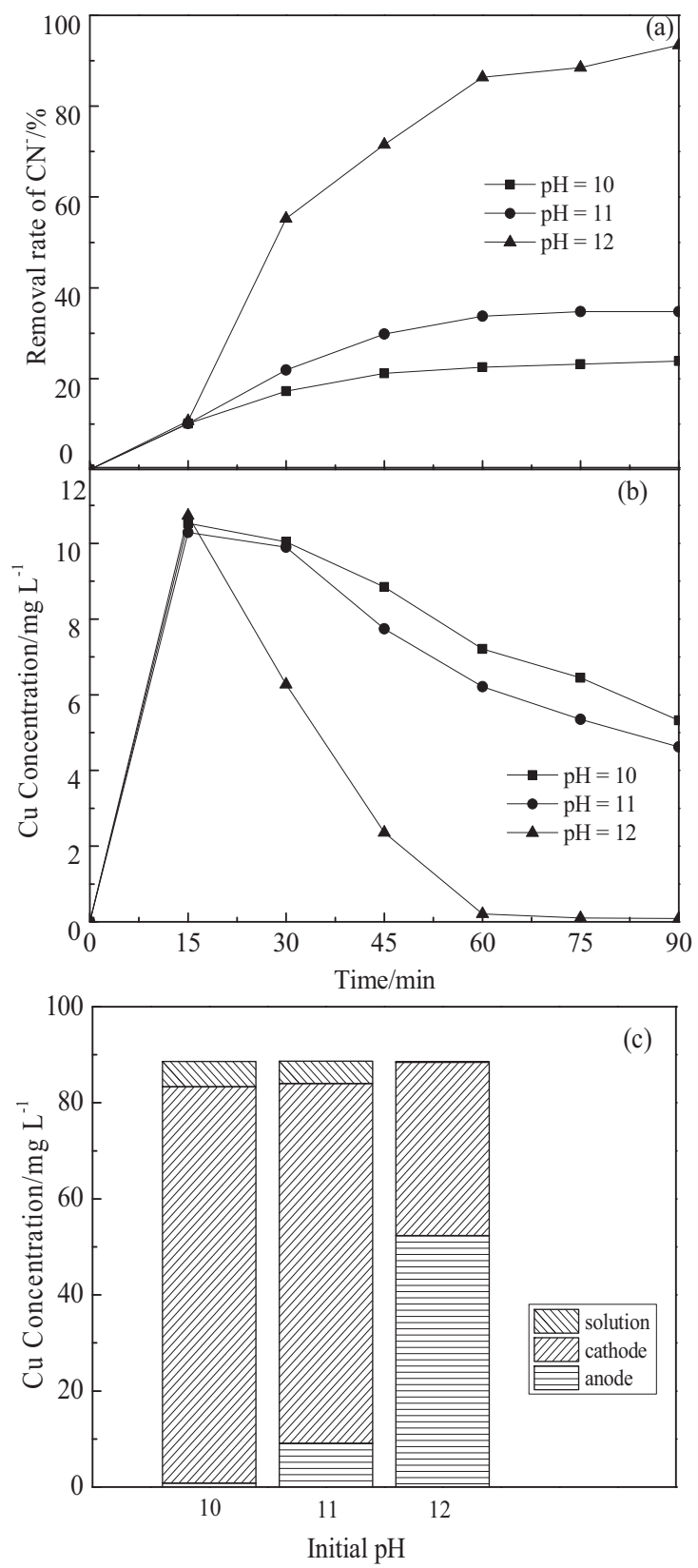

Fig. 3. Effect of $\mathrm{pH}$ on the cyanide removal in the electrochemical process: (a) Variations of the removal rate of cyanide; (b) The $\mathrm{Cu}$ concentration with reaction time; and (c) Copper distribution in the anode, cathode and in solution ([cyanide $]=1.5 \mathrm{mM},[\mathrm{Cu} / \mathrm{ACF}]=1: 1$, current density $=50.01 \mathrm{~A} / \mathrm{m}^{2}$ ). 

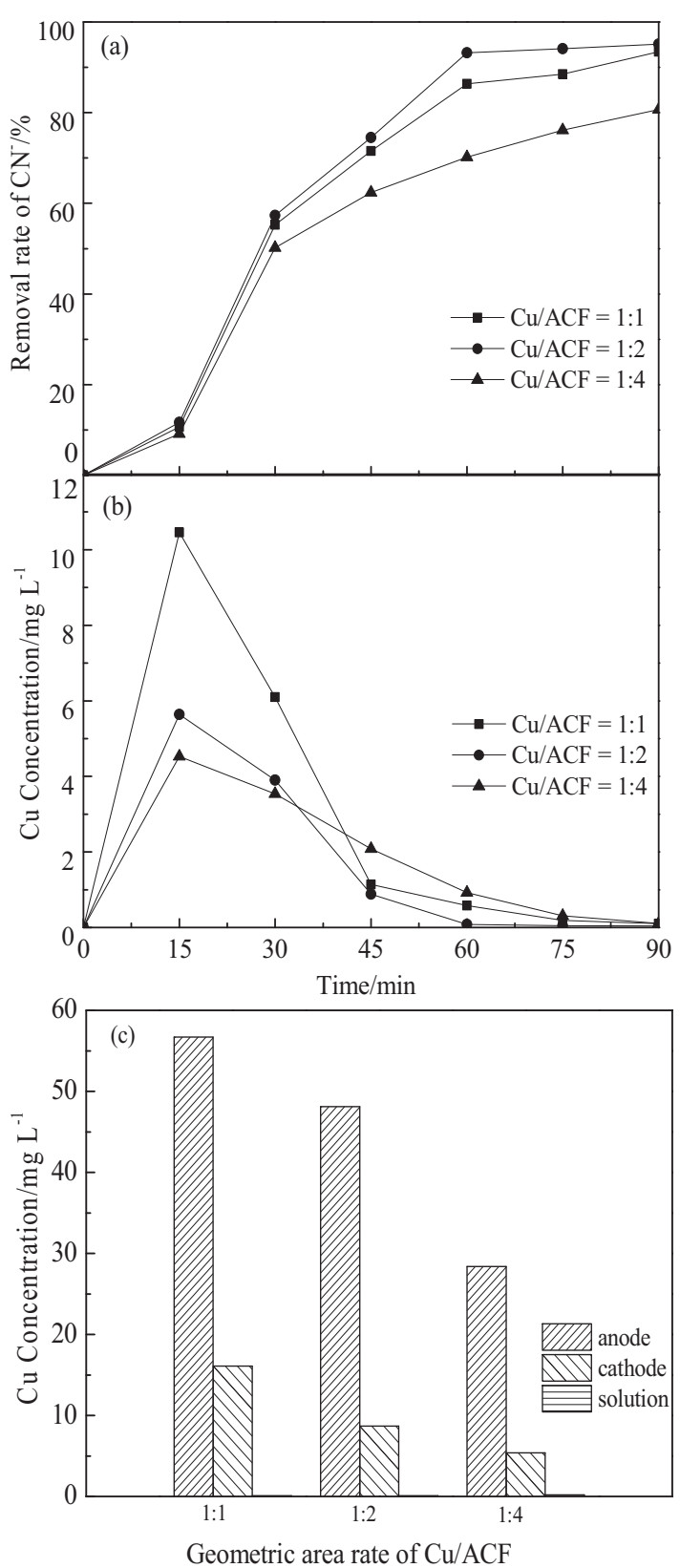

Fig. 4. Effect of geometry area ratio of $\mathrm{Cu} / \mathrm{ACF}$ on the cyanide removal in the electrochemical process: (a) the removal rate of cyanide; (b) The Cu concentration with reaction time; and (c) Copper mass distribution on the anode, cathode and in solution $\left([\right.$ cyanide $]=1.5 \mathrm{mM}, \mathrm{pH}=12.0$, current density $=50.01 \mathrm{~A} / \mathrm{m}^{2}$ ).

experimental conditions. It can be seen from Fig. 2(a), the cyanide removal rate by the stainless steel and activated carbon fibers are limited. With the copper plate cathode, the cyanide removal efficiency can reach up to $50 \%$. When the $\mathrm{Cu} / \mathrm{ACF}$ is used as the cathode, it is noticed that the cyanide removal rate is largely increased to be $93 \%$.

In the case of ACF used as the cathode, in situ generation of $\mathrm{H}_{2} \mathrm{O}_{2}$ could occur. However, When the solution $\mathrm{pH}$ was higher than 10.0, the generated $\mathrm{H}_{2} \mathrm{O}_{2}$ could be decomposed to $\mathrm{HO}_{2}{ }^{-}$. $\mathrm{HO}_{2}{ }^{-}$anions had good stability, but its oxidation potential was lower than $\mathrm{H}_{2} \mathrm{O}_{2}$ [28]. Therefore, using ACF as the cathode generating $\mathrm{H}_{2} \mathrm{O}_{2}$ is limited for the cyanide oxidation. With respect to the stainless steel cathode, individual anodic oxidation occurs, which is also limited for the cyanide oxidation removal. When $\mathrm{Cu} / \mathrm{ACF}$ is used as the cathode, it is known that $\mathrm{H}_{2} \mathrm{O}_{2}$ can be in situ generated via an
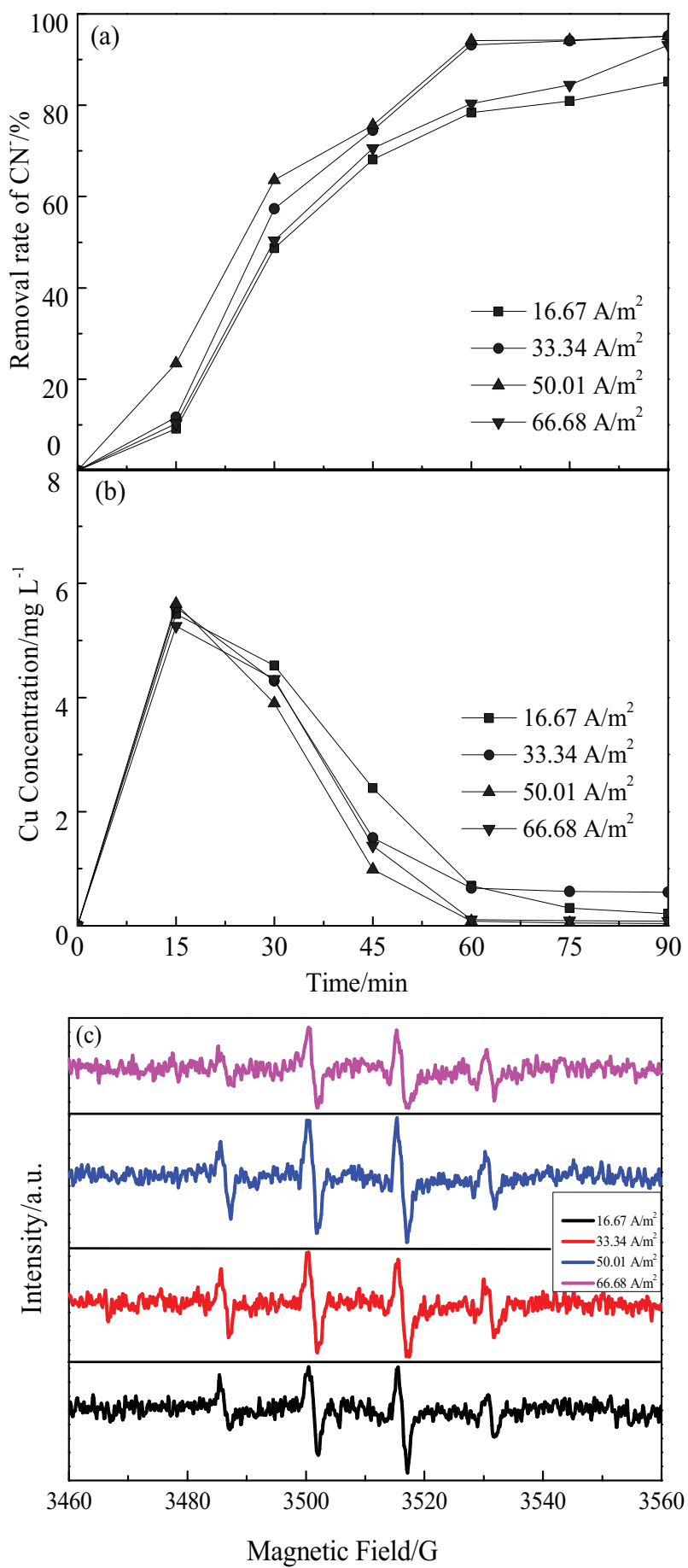

Fig. 5. Effect of current density on the cyanide removal in the electrochemical process: (a) the removal rate of cyanide; (b) The $\mathrm{Cu}$ concentration with reaction time; and (c) ESR spectra ([cyanide $]=1.5 \mathrm{mM},[\mathrm{Cu} / \mathrm{ACF}]=1: 2, \mathrm{pH}=12.0$ ).

electroreduction process when ACF is used as cathode with the $\mathrm{O}_{2}$ injection. In the current case, the $\mathrm{O}_{2}$ is generated by the anodic oxidation of $\mathrm{OH}^{-}$. Therefore, in the case of the $\mathrm{Cu} / \mathrm{ACF}$ cathode, in situ generated $\mathrm{H}_{2} \mathrm{O}_{2}$ may react with the copper cyanide complexes, which increases the cyanide oxidation efficiencies as described in our previous work [29]. Black $\mathrm{CuO}$ is observed at the anode surface, which will be carefully analyzed subsequently. It had been reported that the $\mathrm{CuO}$ deposited on the anode exhibited 

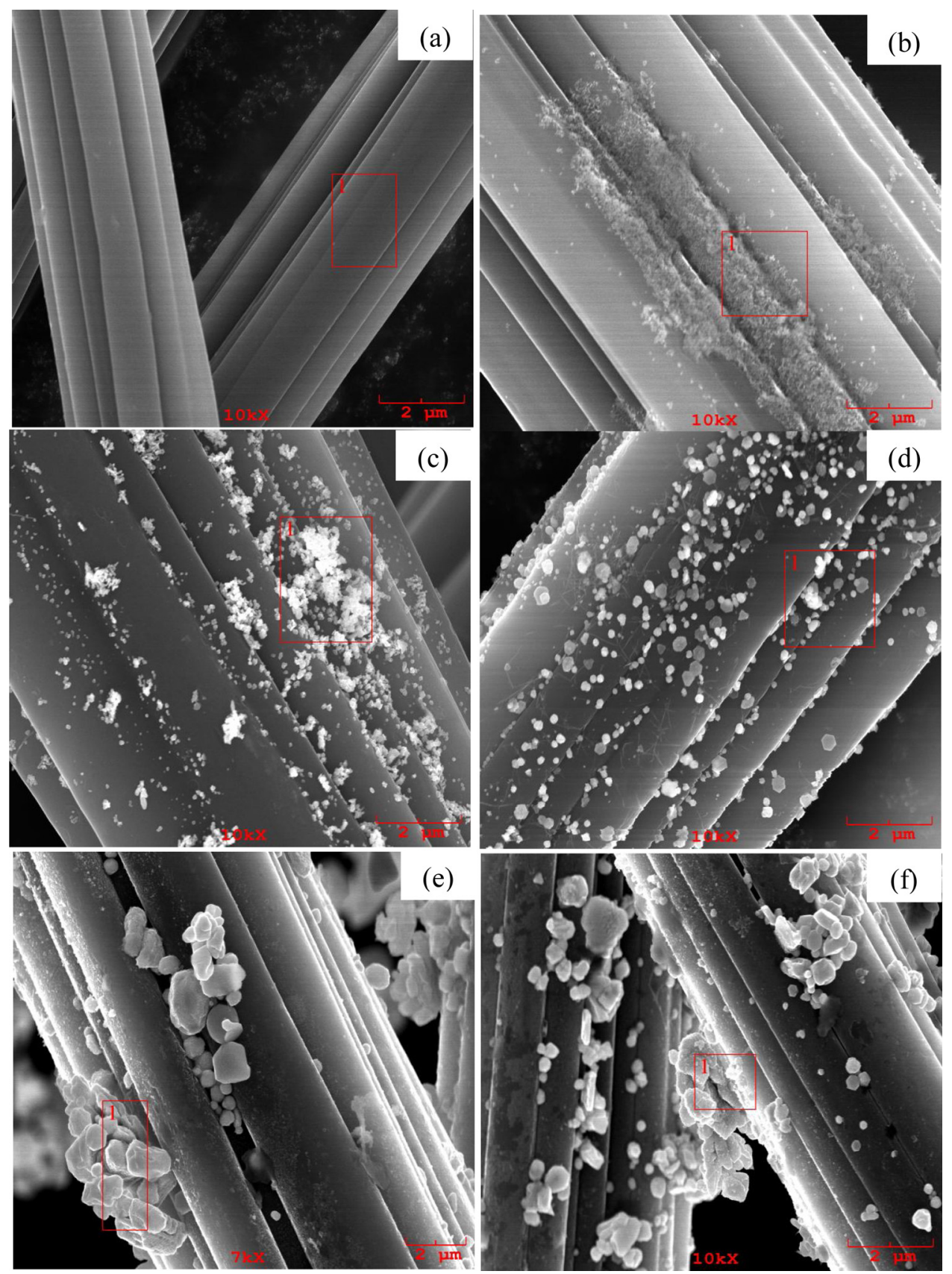

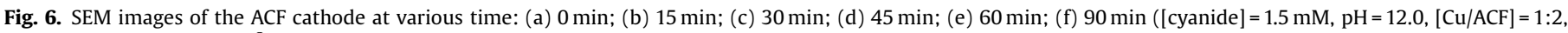
current density $=50.01 \mathrm{~A} / \mathrm{m}^{2}$ ).

electrocatalytic properties for the cyanide oxidation. At the same time, the reduction of $\mathrm{Cu}$ ions in solution occurs at the cathode.

The concentration of the total $\mathrm{Cu}$ ions in the reaction solution is measured with the reaction evolution. As shown in Fig. 2(b), within 15 minutes, the $\mathrm{Cu}$ ions concentration are largely increased to be as high as $10 \mathrm{mg} / \mathrm{L}$. The copper dissolution and deposition process simultaneously occur. In the beginning, the cyanide contributed to dissolution of copper ions and the dissolution rate was higher than deposition rate in electrode. But with the cyanide removing, the deposition rate in electrode was higher than dissolution rate. When injecting $\mathrm{N}_{2}$ into the reaction solution to remove dissolved molecular oxygen, the cyanide removal rate is obviously decreased (Fig. 2(a)). But, the liberation of the $\mathrm{Cu}$ ions from the copper plate into the reaction solution are not influenced.
In addition, the intermediates are also identified. As shown in Fig. 2(c), cyanide is oxidized to non-toxic cyanate. It is obvious that the combined $\mathrm{Cu} / \mathrm{ACF}$ is a favorable cathode material for the cyanide removal, which is selected in the following experiments.

\subsection{Effect of $\mathrm{pH}$ on cyanide removal rate}

Effect of $\mathrm{pH}$ on the cyanide removal is investigated. In order to avoid the cyanide volatilization, the $\mathrm{pH}$ is selected in the range of 10.0-12.0. It can be seen from Fig. 3(a) that there is no obvious difference of the cyanide removal under various $\mathrm{pH}$ conditions within the first 15 minutes. After that, an obvious change for the cyanide removal rate is observed. The cyanide removal rate increases with the $\mathrm{pH}$ and reaches to the maximum at $\mathrm{pH}$ 12.0. 

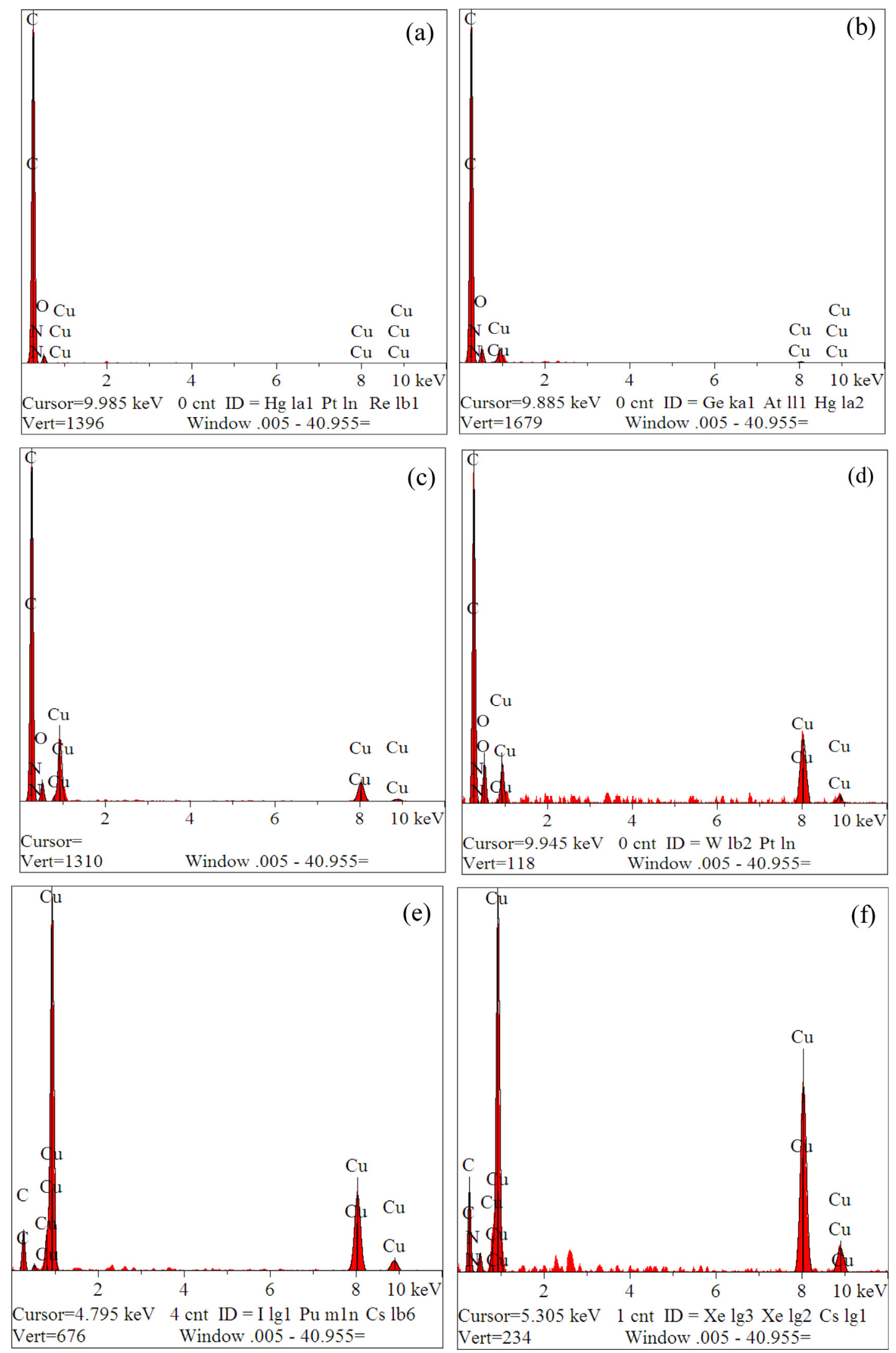

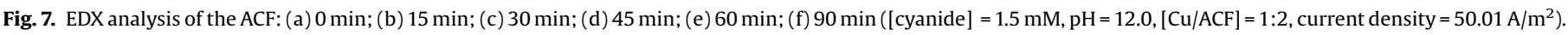



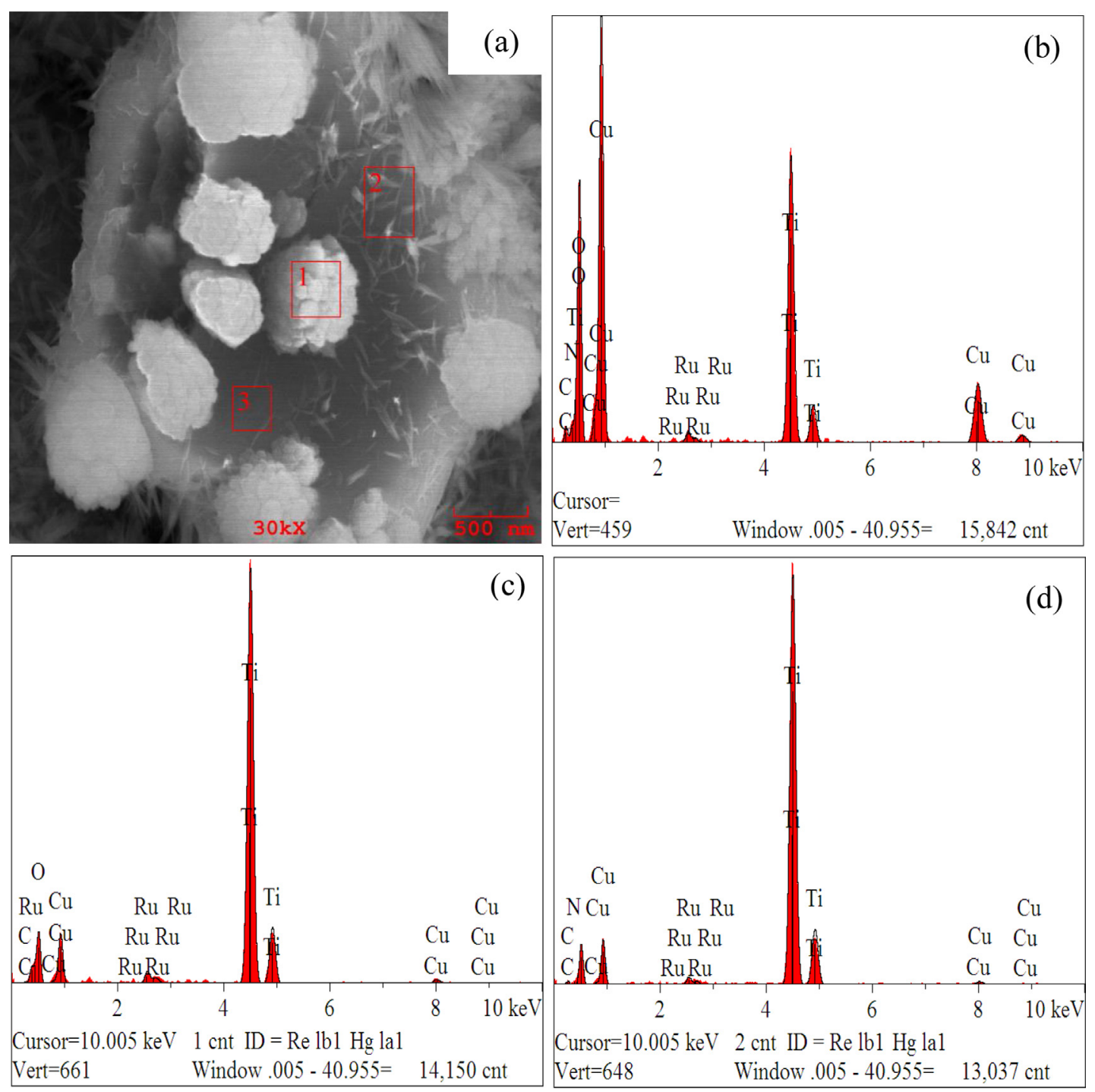

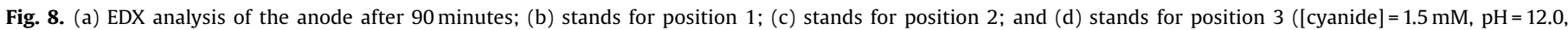
$[\mathrm{Cu} / \mathrm{ACF}]=1: 2$, current density $=50.01 \mathrm{~A} / \mathrm{m}^{2}$ ).

Meantime, the concentration of $\mathrm{Cu}$ ions reaches the largest value at 15 minutes. After that, the concentration of $\mathrm{Cu}$ ions decreases obviously. When the $\mathrm{pH}$ is 12.0 , after 60 minutes, the $\mathrm{Cu}$ ions concentration reaches the lowest value (Fig 3(b)). If cyanide in the solution is not completely removed, copper ions could be dissolved by cyanide and form copper cyanide complexes. Therefore, the higher removal rate of cyanide, the lower concentration of $\mathrm{Cu}$ ions remained in the solution.

Furthermore, the mass distribution of $\mathrm{Cu}$ species in the solution, at the anode and cathode is analyzed at various $\mathrm{pH}$ conditions. The amounts of copper ions deposited on the anode and ACF was dissolved by dilute nitric acid and then measured by ICP-OES. As shown in Fig. 3(c), at the initial pH of 10.0, the concentration of $\mathrm{Cu}$ ions (by $\mathrm{mg} / \mathrm{L}$ ) deposited onto the anode, in the solution, and deposited onto the cathode are determined to be $0.84,5.32$, and $82.47 \mathrm{mg} / \mathrm{L}$, respectively. With the increasing $\mathrm{pH}$, the $\mathrm{Cu}$ amount deposited onto the cathode and in the solution decreases and the $\mathrm{Cu}$ amount deposited onto the anode increases gradually. At the initial pH of 12.0, the $\mathrm{Cu}$ mass deposited onto the anode and the cathode are determined to be 52.36 and $36.18 \mathrm{mg} / \mathrm{L}$, respectively. Several authors had confirmed that the deposit on the anode was copper oxides, which had catalytic properties towards the cyanide oxidation $[17,30]$. Therefore, the generation of the copper oxides at the anode became easy at a high $\mathrm{pH}$ condition, which was capable of electro-oxidizing hydroxide to oxygen and cyanide to cyanate [20]. Therefore, the optimum $\mathrm{pH}$ is selected to be 12.0 .

\subsection{Geometric area ratio of $C u / A C F$ on cyanide removal rate}

The effect of geometric area ratio of $\mathrm{Cu}$ plate to ACF on the cyanide removal rate is investigated with the area rate of $1: 1,1: 2$, $1: 4$. The geometric area of copper plate not only influenced the concentration of $\mathrm{CuO}$ deposited on anode but also influenced the concentration of $\mathrm{H}_{2} \mathrm{O}_{2}$ generated on cathode. As shown in Fig. 4 (a), when the geometric area ratio of $\mathrm{Cu} / \mathrm{ACF}$ is $1: 2$, the cyanide removal rate is the maximum. Due to the dissolution of copper plate by the cyanide ions, the $\mathrm{Cu}$ ions concentration in the solution increases with the geometric area of copper plate at the initial 15 minutes. After 90 minutes, the $\mathrm{Cu}$ ions concentration with the various geometric area ratios of $\mathrm{Cu} / \mathrm{ACF}$ are determined to be lower than $0.2 \mathrm{mg} / \mathrm{L}$ (Fig. 4(b)). As shown in Fig. 4(c), the concentration of $\mathrm{Cu}$ ions deposited onto the anode are determined to be 56.69, 48.10 , and $28.38 \mathrm{mg} / \mathrm{L}$ corresponding to the geometric area ratio of $\mathrm{Cu}$ plate to ACF $1: 1,1: 2,1: 4$, respectively. Obviously, the concentration of copper oxide deposited on the anode is the 

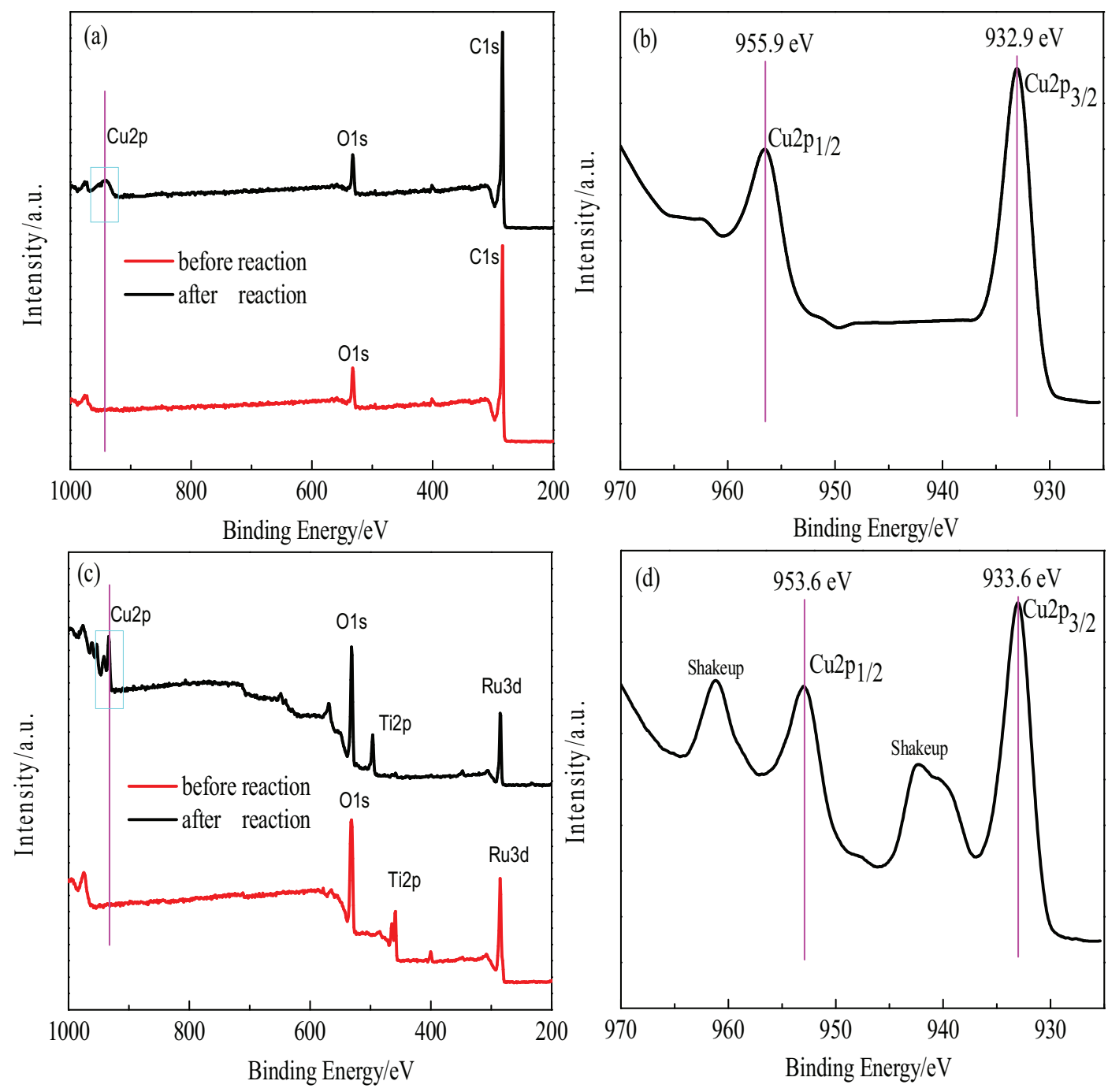

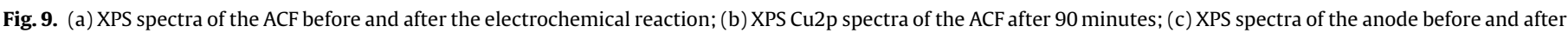
the electrochemical reaction; and (d) Cu2p XPS spectra of the anode after 90 minutes ([cyanide] $=1.5 \mathrm{mM}, \mathrm{pH}=12.0,[\mathrm{Cu} / \mathrm{ACF}]=1: 2, \mathrm{current}$ density $=50.01 \mathrm{~A} / \mathrm{m}^{2}$ ).

maximum with the area ratio of $\mathrm{Cu} / \mathrm{ACF}=1: 1$, but the cyanide removal rate is not the highest. Instead, the cyanide removal rate is the highest at the area ratio of $\mathrm{Cu} / \mathrm{ACF}=1: 2$.

The cyanide removal is induced by the catalytic oxidation via in situ generation of copper oxides on the anode and the Fenton-like oxidation between in situ generation $\mathrm{H}_{2} \mathrm{O}_{2}$ and the copper cyanide complexes. Therefore, the cyanide removal efficiency is related to the concentration of copper oxides amounts deposited on the anode and the $\mathrm{H}_{2} \mathrm{O}_{2}$ amount. At the area ratio of $\mathrm{Cu} / \mathrm{ACF}=1: 1$, the generation amount of $\mathrm{H}_{2} \mathrm{O}_{2}$ decrease due to the low utilization rate of the dissolved molecular oxygen by the ACF cathode. Therefore, the $\mathrm{H}_{2} \mathrm{O}_{2}$ would influence the generation of hydroxyl radicals according to the Eqs. (1)-(3). By contrast, at the $\mathrm{Cu} / \mathrm{ACF}$ area ratio of $1: 4$, the copper oxides catalyst generated at the anode is minimum as shown in Fig. 4 (c). The deposited copper oxides at the anode are beneficial for the cyanide removal. A small amount of generated copper oxides can lead to a decreased cyanide efficiency. According to these results above, the $\mathrm{Cu} / \mathrm{ACF}$ with the geometric area ratio of $1: 2$ is used subsequently.

\subsection{Effect of current density on cyanide removal rate}

It can be seen from Fig. 5(a) that the removal rate of cyanide ions increases slightly with the increasing current density up to
$50.01 \mathrm{~A} / \mathrm{m}^{2}$. After that, the removal rate of cyanide decreases slightly. The cell potential is measured as $1.6 \mathrm{~V}, 3.1 \mathrm{~V}, 4.2 \mathrm{~V}$ and $4.6 \mathrm{~V}$ for the applied current density of $16.67,33.34,50.01$ and $66.68 \mathrm{~A} / \mathrm{m}^{2}$, respectively. At the potential values higher than $4.3 \mathrm{~V}$, the reduction of $\mathrm{O}_{2}$ through Eq. (4) leads to the formation of $\mathrm{H}_{2} \mathrm{O}$ instead of $\mathrm{H}_{2} \mathrm{O}_{2}$ production through Eq. (5) [31]. So, the amount of accumulated $\mathrm{H}_{2} \mathrm{O}_{2}$ decreases in the reaction solution at the current density of $66.68 \mathrm{~A} / \mathrm{m}^{2}$.

$\mathrm{O}_{2}+4 \mathrm{e}^{-}+4 \mathrm{H}^{+}=2 \mathrm{H}_{2} \mathrm{O}$

$\mathrm{O}_{2}+2 \mathrm{e}^{-}+2 \mathrm{H}^{+}=\mathrm{H}_{2} \mathrm{O}_{2}$

Ozcan et al. [32] also reported the same behavior for the $\mathrm{H}_{2} \mathrm{O}_{2}$ production at the potential value higher than $4.3 \mathrm{~V}$. Also, a high potential should be used in order to get a high current density, which accelerates the $\mathrm{H}_{2} \mathrm{O}_{2}$ decomposition either on the anode or in the medium directly (Eqs. (6)-(8)). Moreover, the competitive electrode reactions such as the discharge of $\mathrm{O}_{2}$ and $\mathrm{H}_{2}$ can inhibit $\mathrm{H}_{2} \mathrm{O}_{2}$ generation [33].

$\mathrm{H}_{2} \mathrm{O}_{2} \rightarrow \mathrm{H}_{2} \mathrm{O}+1 / 2 \mathrm{O}_{2}$ 
$\mathrm{H}_{2} \mathrm{O}_{2} \rightarrow \mathrm{HO}_{2}^{\bullet}+\mathrm{H}^{+}+\mathrm{e}^{-}$

$\mathrm{HO}_{2} \cdot \mathrm{O}_{2}+\mathrm{H}^{+}+\mathrm{e}^{-}$

A similar variation trend for the copper ions concentration in the solution with the current densities is observed in Fig. 5(b). Furthermore, the peak intensity of $\bullet \mathrm{OH}$ radicals also exhibit similar variation (Fig. 5(c)). At the current density of $50.01 \mathrm{~A} / \mathrm{m}^{2}$, the peak intensity of $\bullet \mathrm{OH}$ is the largest, which can lead to the efficient destruction of copper cyanides.

\subsection{XPS and SEM-EDX analysis}

The surface variation of the ACF in the cyanide removal process is analyzed by SEM and EDX. As shown in Fig. 6 and Fig. 7, no copper is observed at the surface of the ACF before the electrochemical reaction. In the process of reaction, copper ions reduction occurs onto the cathode. According to the EDX analysis, the proportion of copper in ACF for different time is determined to be $0 \%, 12.6 \%, 30.99 \%, 41.64 \%, 80.94 \%, 81.92 \%$, respectively (Fig. 7). Meantime, deposit sediment on the anode after 90 minutes reaction are observed according to the EDX analysis. According to Fig. 8, the major elements on the anode are $\mathrm{Cu}, \mathrm{Ti}$, $\mathrm{Ru}$ and $\mathrm{O}$.

XPS technique is used to determine the value state of copper deposition on electrode. It has been seen clearly from Fig. 9(a) that the major elements on the ACF before the electrochemical reaction are $\mathrm{C}$ and $\mathrm{O}$. After 90 minutes, peaks of $\mathrm{Cu}$ appeared on the spectra of ACF. Fig. 9(b) shows the XPS spectra of the Cu2p core level binding energy after 90 minutes oxidation reaction. The major $\mathrm{Cu}_{2} \mathrm{p}_{3 / 2}$ peaks centered at $932.9 \mathrm{eV}$ and major $\mathrm{Cu} 2 \mathrm{p}_{1 / 2}$ peaks centered at $955.9 \mathrm{eV}$ are assigned to zero-valent copper. Thus, it is concluded that the copper ions in the reaction solution are reduction onto the cathode by the electrochemical process.

It can been seen clearly from Fig. 9(c) that the major elements on the anode are $\mathrm{Ru}, \mathrm{Ti}$, and $\mathrm{O}$, which are consisted with the anode material of $\mathrm{RuO}_{2} / \mathrm{Ti}$ mesh. After 90 minutes, $\mathrm{Cu}$ peak appears on the anode, which could be ascribed to the generated copper oxides on the anode surface. Fig. 9(d) shows the XPS spectra of the Cu2p core level binding energy after the electrochemical oxidation reaction for 90 minutes. The major $\mathrm{Cu} 2 \mathrm{p}_{3 / 2}$ peaks centered at $933.6 \mathrm{eV}$ and major $\mathrm{Cu} 2 \mathrm{p}_{1 / 2}$ peaks centered at $953.6 \mathrm{eV}$ are assigned to $\mathrm{CuO}$ [34,35].

\subsection{Stability of the electrochemical system}

Stability of the system for the cyanide removal is studied by the repeated use of the same $\mathrm{Cu} / \mathrm{ACF}$ cathode sample for four successive cycles. Before each cycle, the anode and cathode are washed with deionized water. As shown in Fig. 10(a), in the second cycle, the cyanide removal efficiency decreases slightly comparing with the first cycle. However, it remains nearly constant for the second, third and fourth cycle. The efficiencies of the cyanide removal for each cycle are determined to be $93 \%, 80 \%, 76 \%$ and $75 \%$, respectively. As shown in Fig. 10(b), the same variation trend of the $\mathrm{Cu}$ ions concentration is also observed for the four cycles. Copper ions dissolved from copper plate by cyanide ions resulted in the formation of copper cyanides. When the cyanide was oxidized, the copper ions was generated to copper oxide film deposited on the anode and reduced to zero-valent copper. Therefore, the $\mathrm{Cu}$ ions concentration would decrease in Fig. 10(b).

The copper oxide film deposited on the anode is dissolved again when the cyanide concentration is higher than $1 \mathrm{mM}$, leading to the generation of copper cyanide complexes, which is beneficial for
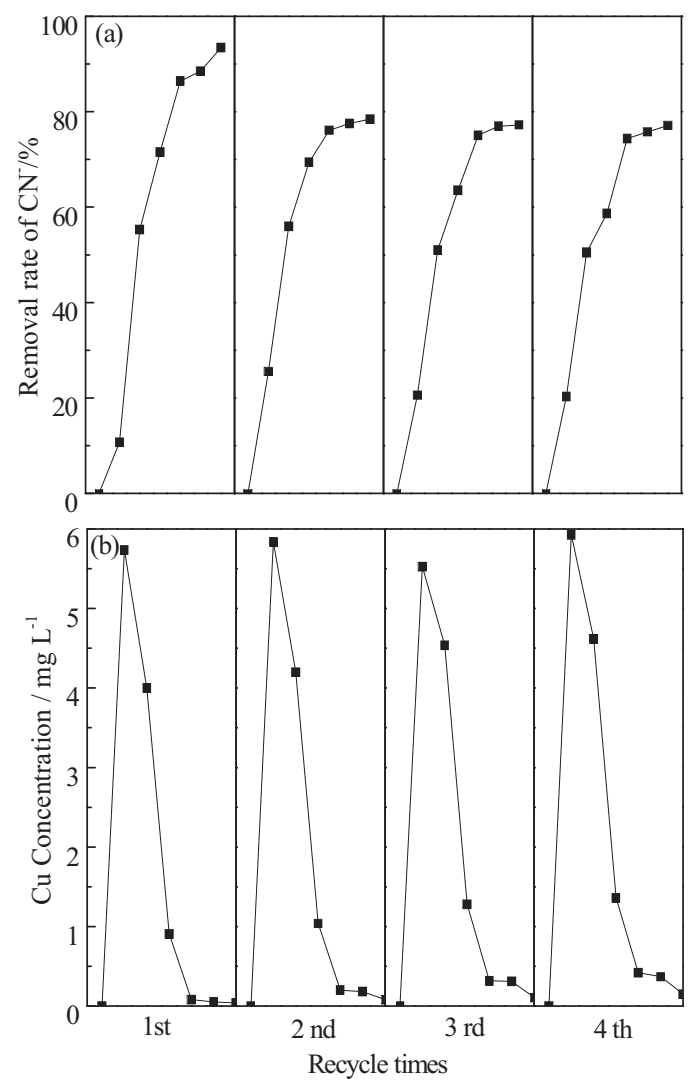

Fig. 10. (a) The removal rate of cyanide for cycles; (b) The Cu concentration in the solution for cycles $([$ cyanide $]=1.5 \mathrm{mM}, \mathrm{pH}=12.0,[\mathrm{Cu} / \mathrm{ACF}]=1: 2$, current density $=$ $50.01 \mathrm{~A} / \mathrm{m}^{2}$ ).

the cyanide removal. Thus, the system exhibits high stability for cyanide removal and copper recovery.

\section{Conclusions}

In this work, the efficient removal of cyanide is achieved in the electrochemical process using the composite cathode of $\mathrm{Cu} / \mathrm{ACF}$. In the cyanide removal process, the $\mathrm{Cu}$ ions are dissolved from the copper plate by the cyanide ions, leading to the formation of copper cyanide complexes. Copper oxides are formed from the copper cyanide complexes oxidation at the anode surface in the electrochemical process, which exhibits catalytic activities for the cyanide removal. $\mathrm{H}_{2} \mathrm{O}_{2}$ is in situ generated by the two electron reduction of $\mathrm{O}_{2}$ at ACF surface, which reacts with copper cyanide complexes via a Fenton-like reaction, leading to the efficient removal of cyanide ions. Both of the above processes are responsible for the efficient cyanide removal. The recovery and reuse of copper is also achieved via the electrodeposition of metallic copper onto the cathode. This system exhibited high stability for cyanide removal and copper recovery.

\section{Acknowledgments}

This work was supported by National Natural Science Foundation of China (No. 21377148,51438011, 51222802).

\section{References}

[1] N. Adhoum, L. Monser, Removal of cyanide from aqueous solution using impregnated activated carbon, Chem. Eng. Process 41 (2002) 17-21. 
[2] X. Dai, P.L. Breuer, M.I. Jeffrey, Comparison of activated carbon and ionexchange resins in recovering copper from cyanide leach solutions, Hydrometallurgy 101 (2010) 48-57.

[3] W. Zhang, W. Liu, Y. Lv, B. Li, W. Ying, Enhanced carbon adsorption treatmen for removing cyanide from coking plant effluent, J. Hazard. Mater. 184 (2010) 135-140.

[4] A. Behnamfrad, M.M. Salarirad, Equilibrium and kinetic studies on free cyanide adsorption from aqueous solution by activated carbon. J. Hazard. Mater. 170 (2009) 127-133.

[5] G. Moussavi, F. Majidi, M. Farzadkia, The influence of operational parameters on elimination of cyanide from wastewater using the electrocoagulation process, Desalination 280 (2011) 127-133.

[6] A. Gupta, E.F. Johnson, R.H. Schlossel, Investigation into the ion exchange of the cyanide complexes of zinc (2+) cadmium (2+), and copper (1+) ions, Ind. Eng. Chem. Res. 26 (1987) 588-594.

[7] G.E. Eden, B.L. Hampson, A.B. Wheatland, Destruction of cyanide in waste waters by chlorination, J. Chem. Technol. Biotechnol. 69 (1950) 244-249.

[8] X. Yang, C. Shang, Chlorination byproduct formation in the presence of humic acid, model nitrogenous organic compounds, ammonia, and bromide, Environ. Sci. Technol. 38 (2004) 4995-5001.

[9] F. Barriga-Ordonez, F. Nava-Alonso, A. Uribe-Salas, Cyanide oxidation by ozone in a steady-state flow bubble column, Miner. Eng. 19 (2006) 117-122.

[10] U.B. Ogutveren, E. Toru, S. Koparal, Removal of cyanide by anodic oxidation for wastewater treatment, Water Res. 33 (1999) 1851-1856.

[11] S.C. Cheng M. Gattrell, T. Guena, B. MacDougall, The electrochemical oxidation of alkaline copper cyanide solutions, Electrochim. Acta 47 (2002) 3245-3256.

[12] M.A. Barakat, Y.T. Chenb, C.P. Huang, Removal of toxic cyanide and Cu (II) Ions from water by illuminated $\mathrm{TiO}_{2}$ catalyst, Appl. Catal. B 53 (2004) 13-20.

[13] M.J. Lopez-Munoz, J. Aguado, R. van Grieken, J. Marugan, Simultaneous photocatalytic reduction of silver and oxidation of cyanide from dicyanoargentate solutions, Appl. Catal. B 86 (2009) 53-62.

[14] V.K. Sharma, W. Rivera, J.O. Smith, Ferrate(VI) oxidation of aqueous cyanide, Environ. Sci. Technol. 32 (1998) 2608-2613.

[15] V.K. Sharma, C.R. Burnett, R.A. Yngard, D.E. Cabelli, Iron (VI) and iron (V) oxidation of copper (I) cyanide, Environ. Sci. Technol. 39 (2005) 3849-3854.

[16] P. Oulego, A. Laca, M. Diaz, Kinetics and pathways of cyanide degradation at high temperatures and pressures, Environ. Sci. Technol. 47 (2012) 1542-1549.

[17] L. Szpyrkowicz, F. Zilio-Grandi, S.N. Kaul, S. Rigoni-Stern, Electrochemical treatment of copper cyanide wastewaters using stainless steel electrodes, Water Sci. Technol. 38 (1998) 261-268.

[18] N. Kuyucak, A. Akcil, Cyanide and removal options from effluents in gold mining and metallurgical processes, Miner. Eng. 50 (2013) 13-29.

[19] L. Szpyrkowicza, G.H. Kelsall, R.M. Souto, F Ricci, Hydrodynamic effects on the performance of an electrochemical reactor for destruction of copper cyanidePart 1: in situ formation of the electrocatalytic film, Chem. Eng. Sci. 60 (2005) 523-533.

[20] M. Sarla, M. Pandit, D.K. Tyagi, J.C. Kapoor, Oxidation of cyanide in aqueous solution by chemical and photochemical process, J. Hazard. Mater. 116 (2004) 49-56.
[21] N. Kishimoto, Y. Nakamura, M. Kato, H. Otsu, Effect of oxidation-reduction potential on an electrochemical Fenton-type process, Chem. Eng. J. 260 (2015) 590-595.

[22] H.J. Park, T.T. Nguyen, J. Yoon, C. Lee, Role of reactive oxygen species in Escherichia coli inactivation by cupric ion, Environ. Sci. Technol. 46 (2012) 11299-11304.

[23] T.T. Nguyen, H.J. Park, J.Y. Kim, H.E. Kim, H. Lee, J. Yoon, C. Lee, Microbial inactivation by cupric ion in combination with $\mathrm{H}_{2} \mathrm{O}_{2}$ : role of reactive oxidants, Environ. Sci. Technol. 47 (2013) 13661-13667.

[24] F.Y. Chen, X. Zhao, H.J. Liu, J.H. Qu, Enhanced destruction of $\mathrm{Cu}(\mathrm{CN})_{3}{ }^{2-}$ by $\mathrm{H}_{2} \mathrm{O}_{2}$ under alkaline conditions in the presence of EDTA/pyrophosphate, Chem. Eng. J. 253 (2014) 478-485.

[25] G.S. Xia, Y.H. Lua, H.B. Xua, Electrogeneration of hydrogen peroxide for electroFenton via oxygen reduction using polyacrylonitrile-based carbon fiber brush cathode, Electrochim. Acta (2015) .

[26] J.M. Monteagudo, L. Rodriguez, J. Villasenor, Advanced oxidation processes for destruction of cyanide from thermoelectric power station waste waters, J. Chem. Technol. Biotechnol. 79 (2004) 117-125.

[27] APHA, AWWA, WEF, Standard Methods for the Examination of Water and Wastewater, 21th ed., APHA, Washington, DC, 2005.

[28] Z.M. Qiang, J.H. Chang, C.P. Huang, Electrochemical generation of hydrogen peroxide from dissolved in acid solutions, Water Res. 36 (2002) 86-94.

[29] F.Y. Chen, X. Zhao, H.J. Liu, J.H. Qu, Reaction of $\mathrm{Cu}(\mathrm{CN})_{3}{ }^{2-}$ with $\mathrm{H}_{2} \mathrm{O}_{2}$ in water under alkaline conditions: Cyanide oxidation, $\mathrm{Cu}^{+} / \mathrm{Cu}^{2+}$ catalysis and $\mathrm{H}_{2} \mathrm{O}_{2}$ decomposition, Appl. Catal. B 158 (2014) 85-90.

[30] L. Szpyrkowicz, S.N. Kaul, E. Molga, M. DeFaveri, Comparison of the performance of a reactor equipped with a Ti/Pt and an SS anode for simultaneous cyanide removal and copper recovery, Electrochim. Acta 46 (2000) 381-387.

[31] A.R. Khataee, M. Safarpour, M. Zarei, S. Aber, Electrochemical generation of $\mathrm{H}_{2} \mathrm{O}_{2}$ using immobilized carbon nanotubeson graphite electrode fed with air: Investigation of operational parameters, J. Electroanal. Chem. 659 (2011) 6368.

[32] A. Özcana, Y. Sahina, A. Savas Koparal, M.A. Oturan, A comparative study on the efficiency of electro-Fenton process in the removal of propham from water, Appl. Catal. B 89 (2009) 620-626.

[33] I. Yamanaka, T. Hashimoto, R. Ichihashi, K. Otsuka, Direct synthesis of $\mathrm{H}_{2} \mathrm{O}_{2}$ acid solutions on carbon cathode prepared from activated carbon and vaporgrowing-carbon-fiber by a $\mathrm{H}_{2} / \mathrm{O}_{2}$ fuel cell, Electrochim. Acta 53 (2008) 48244832.

[34] P. Ning, J. Qiu, X.Q. Wang, W. Liu, W. Chen, Metal loaded zeolite adsorbents for hydrogen cyanide removal, J. Environ. Sci. 25 (2013) 808-814.

[35] L. Szpyrkowicz, F. Ricci, M.F. Montemor, R.M. Souto, Characterization of the catalytic films formed on stainless steel anodes employed for the electrochemical treatment of cuprocyanide wastewaters, J. Hazard. Mater. 119 (2005) 145-152. 